\title{
RANCANG BANGUN APLIKASI KLASIFIKASI PLAGIARISME DENGAN MEMANFAATKAN MACHINE LEARNING BERBASIS ANDROID Mazmur Triputra ${ }^{1}$, Eri Sasmita Susanto,M.Kom. ${ }^{2}$, Wilia Ismiyarti,S.Kom. ${ }^{3}$
}

\author{
${ }^{1}$ Mahasiswa Informatika, Universitas Teknologi Sumbawa \\ ${ }^{2.3}$ Dosen Informatika, Universitas Teknologi Sumbawa
}

\author{
1mazmurtriputra99@gmail.com, ${ }^{2}$ Eri.sasmita.susanto@uts.ac.id, ${ }^{3}$ wilia.ismiyarti@uts.ac.id
}

\begin{abstract}
Abstraksi
Plagiarisme adalah kegiatan yang meniru pekerjaan orang lain, baik dalam bentuk karya ilmiah, menggambar karya, karya musik dan lain-lain. Dalam pemahaman karya ilmiah adalah hasil penelitian ilmiah yang diterbitkan/ditulis oleh orang atau beberapa orang yang karyanya dapat dianggap bertanggung jawab atas kebenaran. Universitas Teknologi Sumbawa (UTS) adalah sebuah universitas swasta yang terletak di desa Pernek, Moyo hulu, Kabupaten Sumbawa, Provinsi Nusa Tenggara Barat. Memiliki banyak mahasiswa dan dosen di komunitas akademik, pada semester akhir siswa menulis makalah ilmiah adalah salah satu persyaratan kelulusan dalam rangka untuk mendapatkan gelar sarjana (S-1), tetapi masih ada unsur plagiarisme untuk mempercepat proses penulisan makalah ilmiah, bukan hanya mahasiswa tetapi dosen juga mengalami kesulitan membuat jurnal penelitian karena kurangnya tulisan asli yang merupakan bahan untuk membuat jurnal. Penelitian ini bertujuan untuk membangun sebuah aplikasi Android klasifikasi plagariarisme dengan machine learning. Aplikasi ini dikembangkan menggunakan bahasa pemrograman asli Java dengan machine learning Optical Character Recognation (OCR) dan Copyleaks API Cloud computing sebagai pendeteksi plagiat ini dan metode pengembangan perangkat lunak menggunakan Waterfall model. Pengujian perangkat lunak dilakukan melalui pengujian blackbox testing. Instrumen pengumpulan data teknik penelitian menggunakan pengamatan, wawancara, dokumentasi dan studi sastra. Hasil akhir dari penelitian ini adalah desain aplikasi klasifikasi plagiarisme berbasis Android untuk memfasilitasi pembuatan jurnal umum di lembaga penelitian dan layanan masyarakat dan mengurangi unsur plagiarisme dalam membuat karya ilmiah dan penelitian Sumbawa Universitas Teknologi.
\end{abstract}

Kata kunci: Plagiarisme, Machine Lerning, Android, Waterfall

\begin{abstract}
Plagiarism is an activity that mimics the work of others, whether in the form of scientific work, drawing works, musical works and others. In its understanding scientific work is the result of scientific research published I written by people or some people whose work can be held responsible for the truth. Sumbawa University of Technology (UTS) is a private university located in Pernek Village, Moyo Hulu, Sumbawa Regency, West Nusa Tenggara Province. Having many students and lecturers in the academic community, in the final semester students writing scientific papers is one of the graduation requirements in order to get a bachelor's degree (S-1), but there is still an element of plagiarism to accelerate the process of writing scientific papers, not just students but lecturers also had difficulty making a research journal because of the lack of original writing which was the material for making a journal.This research aims to build an android application plagariarism checker with machine learning . The application was developed using the Native Java programming language with machine learning optical character recognation $(O C R)$ features and Copyleaks API cloud computing as a plagiarism cheker's. A method of software development using the Waterfall Model. Software testing is done via black-box testing. The instrument of data collection Techniques on research using observation, interviews, documentation and study of the literature. The end result of this research is design a plagiarism classification application android-based to facilitate the making of general journals in research institutions and community service and reduce the element of plagiarism in making scientific work and research sumbawa university of technology.
\end{abstract}

Keyword: Plagiarism, Machine Learning, Android, Waterfall. 


\section{PENDAHULUAN}

\subsection{Latar Belakang}

Di jaman era globalisasi saat ini, teknologi sudah semakin berkembang dalam semua bidang. Semakin berkembangnya teknologi saat ini semakin memudahkan pekerjaan manusia agar lebih efisien dan cepat. namun sangat disayangkan , ketika sudah maraknya teknologi dan informasi yang begitu cepat, masih saja ada orang yang meniru karya orang lain demi kepentingan pribadi. Salah satunya adalah plagiarisme yang semakin banyak ditemukan dimana-mana.

Plagiarisme atau yang biasa disebut (plagiat) merupakan suatu kegiatan meniru karya orang lain, baik itu berupa karya ilmiah, karya gambar, karya musik dan lain-lain. Dalam pengertiannya karya ilmah merupakan hasil dari penelitian ilmiah yang diterbitkan/ditulis oleh orang atau beberapa orang yang hasil karyanya bisa di tanggung jawabkan kebenarannya. Di perguruan tinggi khususnya pada jenjang Strata satu (S-1) mahasiswa dilatih untuk membuat karya ilmiah yang disebut skripsi. Skripsi merupakan sebuah karya ilmiah yang dibuat oleh mahasiswa jenjang Strata satu (S-1) sebagai salah satu syarat kelulusan untuk jenjang Strata satu (S-1) yang didalamnya terdapat sebuah filosofis dari penelitian yang terdapat permasalahan disertai dengan tinjauan analisis dengan menggunakan metode penelitian tertentu yang digunakan untuk memecahkan suatu permasalahan secara teoritis dan terstruktur.

Universitas Teknologi Sumbawa (UTS) merupakan perguruan tinggi swasta yang terletak di Desa Pernek, Kecematan Moyo Hulu, Kabupaten Sumbawa, Provinsi Nusa Tenggara Barat. Memiliki banyak mahasiswa dan dosen di lingkungan civitas akademika, pada mahasiswa semester akhir penulisan karya ilmiah merupakan salah satu syarat kelulusan agar mendapatkan gelar Strata 1 (S-1), Tetapi masih ada unsur plagiarisme yang dilakukan guna untuk mempercepat proses penulisan karya ilmiah, bukan hanya mahasiswa tetapi dosen pun kesulitan membuat sebuah jurnal penelitian karena kurangnya tulisan orisinil yang merupakan bahan untuk membuat sebuah jurnal.

Oleh karena itu penulis membuat sebuah karya ilmiah tentang "Rancang bangun Aplikasi klasifikasi Plagiarisme Karya Ilmiah dengan Memanfaatkan Machine Learning Berbasis Android", karya ilmiah ini dapat dimanfaatkan oleh dosen hanya melalui sebuah aplikasi. Selain kemudahan yang diterima dosen atau peneliti dalam mengetahui karya ilmiah tersebut plagiarisme atau bukan, juga untuk membantu para dosen untuk membuat jurnal secara lengkap tanpa adanya plagiarisme sehingga kedepannya jurnal yang dibuat berguna bagi yang membutuhkannya.

Dengan adanya aplikasi ini diharapkan dapat berkurangnya unsur plagiarisme bagi mahasiswa yang sedang menulis karya ilmiah, kemudian bagi dosen dapat mempermudah dalam pembuatan suatu jurnal yang baik yang berkualitas dan juga aplikasi ini berbasis android, sehingga mudah di akses bagi pengguna smartphone yang berbasis android.

\subsection{Batasan Masalah}

Adapun perumusan masalah yang telah didefinisikan agar menjadi lebih tepat dan terperinci sesuai harapan yang diinginkan, maka dilakukan pembatasan masalah yaitu antara lain sebagai berikut:

1. Studi kasus dilakukan pada Lembaga Penelitian dan pengabdian Masyarakat (LPPM) Universitas Teknologi Sumbawa dengan Dosen, untuk mengetahui seberapa besar tingkat plagiarisme yang terjadi pada perancangan karya ilmiah mahasiswa.

2. Aplikasi yang dibangun menggunakan fitur machine learning Scan OCR text dan text input.

3. Pengembangan perangkat lunak menggunakan metode waterfall Devolopment Model.

4. Bahasa pemrograman yang digunakan yaitu Android Mobile menggunakan menggunakan salah satu fitur machine learning Scan OCR, Copyleaks API Clasification cloud computing dan Java menggunakan Android Studio serta pengujian aplikasi menggunakan blackbox testing.

5. Dalam pembuatan aplikasi klasifikasi plagiarisme karya ilmiah ini membahas alur program, penelitian, perancangan sistem dan implementasi aplikasi.

\subsection{Tujuan Penelitian}

Membangun Aplikasi klasifikasi plagiarisme untuk Universitas Teknologi Sumbawa agar digunakan Dosen untuk mendeteksi unsur plagiarisme pada karya ilmiah mahasiswa.

\subsection{Manfaat Penelitian}

Adapun manfaat dari penelitian ini yang di bagi menjadi dua yaitu manfaat praktis dan manfaat teoritis sebagai berikut:

\section{a. Manfaat Praktis}

Membantu lembaga penelitian dan pengabdian masyarakat (LPPM) mengklasifikasikan jurnal penelitian dan karya ilmiah.

\section{b. Manfaat Teoritis}

Hasil penelitian ini diharapkan secara teoritis dapat memberikan sumber referensi dan informasi bagi penelitian selanjutnya yang berkaitan dengan mengklasifikasikan unsur plagiarisme pada karya ilmiah dan jurnal penelitian. 


\subsection{Sistematika Penulisan}

Untuk memberi gambaran tentang penelitian ini, maka disusunlah suatu sistematika penulisan berisi tentang materi yang dibahas disetiap bab pembahasan.

\section{LANDASAN TEORI}

\subsection{Tinjauan Pustaka}

Plagiarisme atau sering disebut plagiat adalah penjiplakan atau pengambilan karangan, pendapat, dan sebagainya dari orang lain dan menjadikannya seolah karangan dan pendapat sendiri (KBBI, 1997). "Plagiarisme adalah bentuk penyalahgunaan hak kekayaan intelektual milik orang lain, yang mana karya tersebut dipresentasikan dan diakui secara tidak sah sebagai hasil karya pribadi” (Sulianta, 2007).

\subsection{Dasar Teori}

Adapun dasar teori yang mendukung dalam pembuatan laporan ini sebagai berikut:

\subsubsection{Rancang Bangun}

Rancang bangun adalah penggambaran, perencanaan, dan pembuatan sketsa atau pengaturan dari beberapa elemen yang terpisah kedalam satu kesatuan yang utuh dan berfungsi. (Jogiyanto, 2001:196).

Dengan demikian pengertian rancangan bangun adalah hasil analisa dalam bentuk perangkat lunak yang digunakan untuk menyelesaikan masalah-masalah dengan menciptakan atau memperbarui sistem menggunakan kemampuan computer

\subsubsection{Aplikasi}

Aplikasi adalah penggunaan dalam suatu perangkat komputer, instruksi (instruction) atau pernyataan (statement) yang disusun hingga sedemikian rupa komputer dapat memproses masukan (input) menjadi keluaran (output).(Rizal dkk, 2013)

\subsubsection{Unified Modeling Language (UML)}

Unified Modeling Language adalah bahasa standar untuk pemodelan perangkat lunak yang digunakan untuk model proses bisnis dan muncul sebagai standar umum untuk pemodelan berorientasi objek (Booch, 2005:7). Pemodelan $U M L$ menggunakan diagram sebagai berikut:

\section{Use Case Diagram}

Diagram Use Case yang digunakan untuk menganalisis interaksi yang di sediakan pada antar muka aplikasi yang menggambarkan subuah interaksi sistem dan aktor.

\section{Activity Diagram}

Activity diagram merupakan pemodelan yang dari seluruh proses yang terjadi pada sistem.

\section{Squence Diagram}

Sequence diagram yang merupakan diagram yang mejelaskan interaksi pada objek berdasarkan urutan waktu. Sequence diagram memeliki fokus pada perilaku didalam sistem mengilustrasikan bagaimana objek dan pesan yang dikirim antar projek.

\section{Class Diagram}

Class diagram adalah diagram yang akan digunakan untuk menampilkan kelaskelas atau paket-paket pada sistem yang akan digunakan

\subsubsection{Waterfall}

Waterfall adalah model klasik yang bersifat sistematis, berurutan dalam membangun software. Nama model ini sebenarnya adalah "Linear Sequential Model". Model ini sering disebut juga dengan "classic life cycle" atau metode waterfall. Model ini termasuk ke dalam model generic pada rekayasa perangkat lunak dan pertama kali diperkenalkan oleh Winston Royce sekitar tahun 1970 sehingga sering dianggap kuno, tetapi merupakan model yang paling banyak dipakai dalam Software Engineering (SE). Model ini melakukan pendekatan secara sistematis dan berurutan. Disebut dengan waterfall karena tahap demi tahap yang dilalui harus menunggu selesainya tahap sebelumnya dan berjalan berurutan (Pressman, 2015:42).

\subsubsection{Pengujian Perangkat Lunak}

Pengujian Perangkat Lunak adalah suatu proses yang digunakan untuk mengidentifikasi ketepatan, kelengkapan dan mutu dari perangkat lunak.

Dalam pengujian perangkat lunak, penulis membandingkan dua jenis metode pengujian yaitu Black Box dan White Box.
Tabel 2.1 Perbandingan Pengujian Black box dengan White box 


\begin{tabular}{|c|c|c|}
\hline No & \multicolumn{2}{|c|}{ Metode Perangkat } \\
\hline 1 & \multicolumn{2}{|c|}{ Black Box } \\
\hline & Definisi & 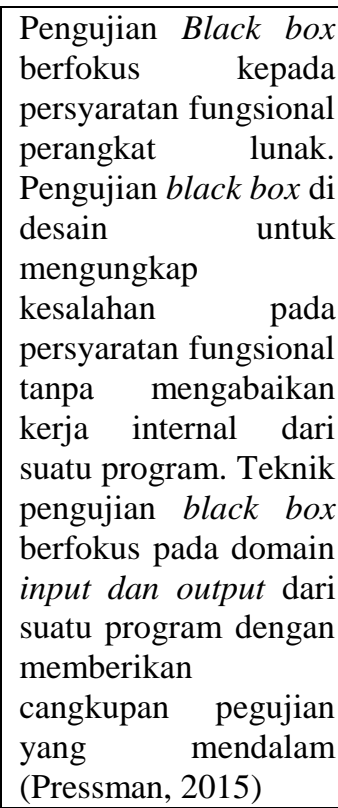 \\
\hline & Kelebihan & $\begin{array}{ll}\text { a. } & \text { Dapat menguji } \\
& \text { keseluruhan } \\
& \text { fungsionalitas } \\
& \text { perangkat lunak } \\
\text { b. } & \text { Dapat memilih } \\
& \text { subset test yang } \\
& \text { secara efektif dan } \\
& \text { efisien dapat } \\
& \text { menemukan } \\
\text { cacat, dengan cara } \\
\text { ini black box } \\
\text { dapat membantu } \\
\text { memaksimalkan } \\
\text { testing investmen. }\end{array}$ \\
\hline & Kekurangan & $\begin{array}{l}\text { Ketika user } \\
\text { melakukan black box } \\
\text { testing user tidak akan } \\
\text { pernah yakin apakah } \\
\text { perangkat lunak yang } \\
\text { diuji telah benar-benar } \\
\text { lolos pengujian. }\end{array}$ \\
\hline \multirow[t]{3}{*}{2} & \multicolumn{2}{|r|}{ White Box } \\
\hline & Definisi & \begin{tabular}{|lr} 
adalah metode desain \\
test case r yang \\
mengunakan struktur \\
kontrol r desain \\
procedural untuk \\
memperoleh & test case. \\
\end{tabular} \\
\hline & Kelebihan & $\begin{array}{ll}\text { a. } & \text { Pengujian kotak } \\
\text { putih memberi } \\
\text { aturan yang jelas, } \\
\text { berbasis teknik, } \\
\text { kapan harus } \\
\text { berhenti } \\
\text { melakukan } \\
\text { pengujian. } \\
\text { b. Optimalisasi kode } \\
\text { dengan } \\
\text { mengungkapkan }\end{array}$ \\
\hline
\end{tabular}

\begin{tabular}{|c|c|c|}
\hline & c. & $\begin{array}{l}\text { kesalahan } \\
\text { tersembunyi dan } \\
\text { mampu } \\
\text { menghapus } \\
\text { kemungkinan } \\
\text { cacat. } \\
\text { Memberikan } \\
\text { intropeksi } \\
\text { programmer } \\
\text { karena para } \\
\text { pengembang } \\
\text { dengan hati-hati } \\
\text { menggambarkan } \\
\text { setiap } \\
\text { implementasi } \\
\text { baru. }\end{array}$ \\
\hline Kekurangan & a. & $\begin{array}{l}\text { Pengujian kotak } \\
\text { putih membawah } \\
\text { kompleksitas } \\
\text { pengujian karena } \\
\text { pengujian harus } \\
\text { memiliki } \\
\text { pengetahuan } \\
\text { tentang program } \\
\text { ini, termasuk } \\
\text { menjadi } \\
\text { pemrogram. } \\
\text { Pengujian kotak } \\
\text { putih } \\
\text { membutuhkan } \\
\text { pemrogram } \\
\text { dengan tingkat } \\
\text { penghetahuan } \\
\text { yang tinggi karena } \\
\text { kompleksitas } \\
\text { tingkat pengujian } \\
\text { yang perlu } \\
\text { dilakukan. } \\
\text { Pada beberapa } \\
\text { kesempatan, tidak } \\
\text { realistis untuk } \\
\text { dapat menguji } \\
\text { setiap kondisi } \\
\text { aplikasi yang ada } \\
\text { dan beberapa } \\
\text { kondisi akan } \\
\text { belum teruji }\end{array}$ \\
\hline
\end{tabular}

\section{METODOLOGI PENELITIAN}

\subsection{Metode Penelitian}

Tahap-tahap yang dilakukan dalam pengumpulan data untuk merancang dan membangun sistem informasi ini dapat digambarkan pada bagan alur sebagai berikut: 


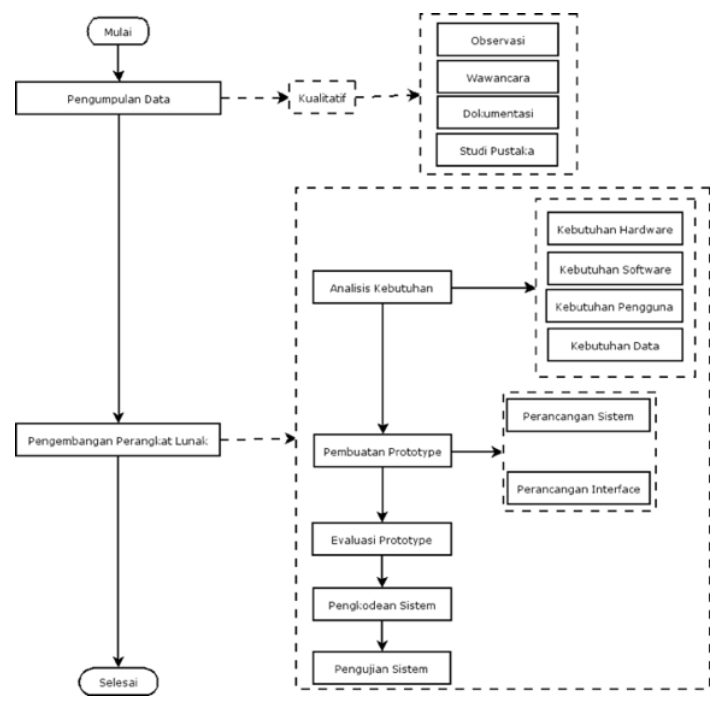

Gambar 3.1 Metode Penelitian

\subsubsection{Metode Pengumpulan Data}

Pada tahapan ini dilakukan pengumpulan data dengan konsep deskriptif dan data kualitatif. Adapun langkah-langkah yang dilakukan adalah dengan menggunakan empat metode yaitu observasi, wawancara, dokumentasi, dan studi pustaka.

\section{Observasi}

Pada metode ini peneliti melakukan survei lokasi Pada metode ini peneliti melakukan survei lokasi di UTS, tepatnya pada bagian Lembaga Penelitian dan Pengabdian Masyarakat (LPPM) UTS untuk mengumpulkan data-data jenis karya ilmiah yang sering terdapat plagiarisme dan contoh jurnal umum yang sudah menjadi jurnal penelitian yang sudah ada. Untuk lebih jelasnya bisa dilihat pada tabel dibawah ini :

Tabel 4.1 Hasil Observasi

\begin{tabular}{|c|l|l|}
\hline \multicolumn{2}{|c|}{ HASIL OBSERVASI } \\
\hline \multirow{2}{*}{ No. } & \multicolumn{1}{|c|}{ Tempat } & Data dari \\
& Observasi & observasi \\
\hline 1. & Kunjungan & \multicolumn{1}{|c|}{ Buku jurnal } \\
& langsung & TAMBORA \\
& Ruangan LPPM. & Tahun 2016, \\
& & $2017, \quad 2018$, \\
& & 2019 \\
\hline
\end{tabular}

\begin{tabular}{|l|l|l|}
\hline 1. & \multicolumn{1}{|c|}{ Bertemu dengan } & \\
& anggota LPPM & Edisi Vol. 1,2 \\
& Universitas &, 3 \\
Teknologi & \\
& Sumbawa & \\
\hline
\end{tabular}

\subsubsection{Metode Pengembangan Perangkat Lunak}

Waterfall adalah model klasik yang bersifat sistematis, berurutan dalam membangun software. Nama model ini sebenarnya adalah "Linear Sequential Model". Model ini sering disebut juga dengan "classic life cycle" atau metode waterfall. Model ini termasuk ke dalam model generic pada rekayasa perangkat lunak dan pertama kali diperkenalkan oleh Winston Royce sekitar tahun 1970 sehingga sering dianggap kuno, tetapi merupakan model yang paling banyak dipakai dalam Software Engineering (SE). Model ini melakukan pendekatan secara sistematis dan berurutan. Disebut dengan waterfall karena tahap demi tahap yang dilalui harus menunggu selesainya tahap sebelumnya dan berjalan berurutan (Pressman, 2015:42).

Tahapan-tahapan dari metode waterfall ini adalah dimulai dari: Analisa kebutuhan, desain sistem, penulisan kode program, pengujian program dan penerapan program, Alur dari metode Waterfall adalah sebagai berikut:

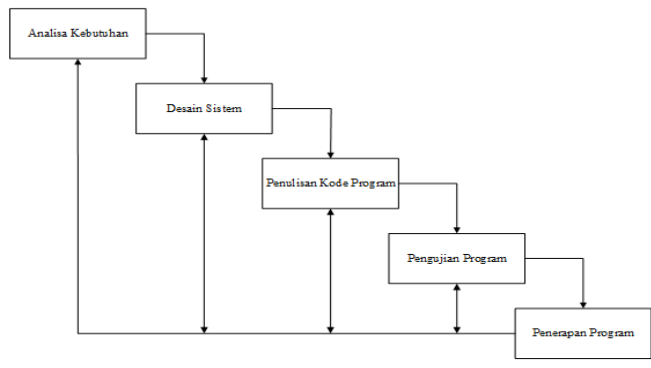

Gambar 3.2 Metode Waterfall

\subsection{Alat Dan Bahan Penelitian}

Alat penelitian yang digunakan dibagi menjadi dua yaitu komponen perangkat keras, perangkat lunak, dan kebutuhan data sebagai pendukung penelitian yang dilakukan, alat ini yang akan dijadikan sebagai alat pengolahan data dan pembuatan sistem yang akan dirancang. 


\section{HASIL DAN PEMBAHASAN}

\subsection{Hasil Pengumpulan Data}

Hasil pengumpulan data yang telah dilakukan dalam penelitian ini sebagai berikut:

\subsubsection{Observasi}

Setelah melakukan observasi terhadap Lembaga Penelitian dan pengabdian Masyarakat (LPPM) Universitas Teknoogi Sumbawa. Pihak LPPM tersebut bersedia memberikan data contoh jurnal tambora yang sudah terbit hingga tahun terakhir sebagai acuan dalam penelitian ini.

\subsubsection{Wawancara}

Pada tahap wawancara dilakukan dengan wawancara langsung. Metode wawancara langsung dilakukan memberikan pertanyaan langsung kepada Kepala LPPM UTS dengan materi pertanyaan yang sudah dibuat oleh penulis yang nantinya dengan adanya hasil wawancara tersebut untuk mendukung dalam pembangunan aplikasi.

\subsubsection{Dokumentasi}

Terdapat contoh 5 sampel dokumen yang merupakan terdapat unsur plagiarisme di LPPM UTS yang telah di ambil untuk dijadikan contoh untuk aplikasi yang akan dibangun.

\subsubsection{Studi Pustaka}

Studi pustaka yang digunakan untuk memperoleh data serta informasi dalam penelitian ini meliputi:

1. Buku referensi yang berhubungan dengan analisa dan desain rancang bangun, pemrograman android, rekayasa perangkat lunak, dan Machine Learning.

2. Jurnal dan tugas akhir yang berkaitan

\subsection{Hasil Analisis Kebutuhan}

Adapun hasil dari analisis kebutuhan dalam membangun sistem informasi pengelolaan data alumni pada SMA Negeri 3 Sumbawa Besar sebagai berikut:

\section{A. Kebutuhan Perangkat Keras (Hardware)}

Adapun kebutuhan perangkat keras yang akan digunakan oleh peneliti dalam pembangunan aplikasi klasifikasi plagiarisme dengan machine learning ini adalah :

Tabel 4.2 Spesifikasi Perangkat Keras (Hardware)

\begin{tabular}{|l|l|}
\hline $\begin{array}{l}\text { Nama } \\
\text { Perangkat }\end{array}$ & \multicolumn{1}{|c|}{ Spesifikasi } \\
\hline Laptop & Memori $($ RAM) 4.00 GB \\
\hline & Processor Intel Core i5 $2.15 \mathrm{GHz}$ \\
\hline & VGA Intel HD 4000 \\
\hline & SSD Hardik 500 Gb \\
\hline
\end{tabular}

\section{b. Kebutuhan Perangkat Lunak} (Software)

Adapun perangkat lunak yang digunakan dalam pembangunan aplikasi klasifikasi plagiarisme dengan machine learning ini adalah:

Tabel 4.2 Spesifikasi Perangkat Lunak (Software)

\begin{tabular}{|l|l|l|}
\hline No & Perangkat Lunak & Spesifikasi \\
\hline 1. & Sistem Operasi & Mac OS \\
\hline 2. & Text Editor & $\begin{array}{l}\text { Android } \\
\text { Studio. }\end{array}$ \\
\hline 3. & Bahasa pemrograman & Java \\
\hline 4. & API & $\begin{array}{l}\text { API } \\
\text { Copyleaks }\end{array}$ \\
\hline 5. & Mesin pencari & Chrome \\
\hline
\end{tabular}

\section{c. Kebutuhan Data}

Adapun kebutuhan data yang dibutuhkan dalam mengelola data-data alumni pada SMA Negeri 3 Sumbawa Besar yaitu data para alumni yang telah di tulis di dalam buku jejak alumni pada angkatan 2015. 2016, 2017 dan 2018.

\section{Perancangan Sistem}

Adapun perancangan sistem dari pembuatan sistem informasi pengelolaan data alumni pada SMA Negeri 3 Sumbawa Besar sebagai berikut:

\section{a. Use Case Diagram}

Adapun Use Case Diagram dari pengelolaan data alumni pada SMA Negeri 3 Sumbawa Besar adalah sebagai berikut:

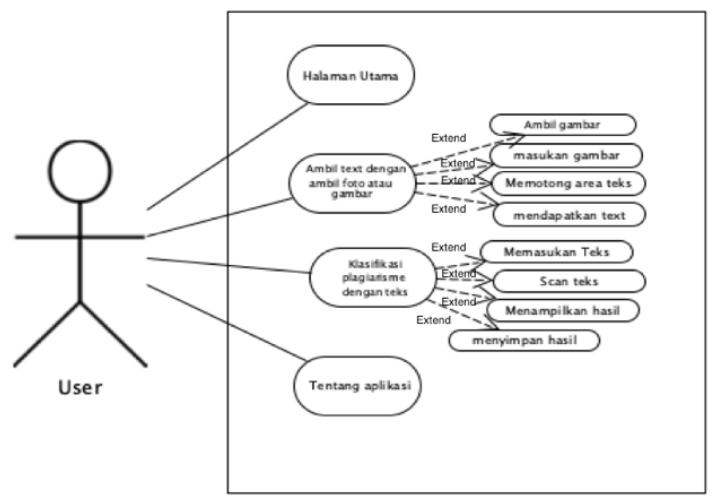

Gambar 4.1 Usecase Diagram user 
Pada Use Case Diagram user diatas, Aplikasi memberikan akses kepada user denga terdapat beberapa menu, yaitu halaman utama, ambil teks dengan dari gambar, klasifikasi plagiat dan tentang aplikasi.

\section{b. Activity Diagram}

Adapun Activity Diagram pada Aplikasi klasifikasi plagiarism dengan machine learning adalah sebagai berikut:

\section{Activity Diagram Halaman Utama Web}

Adapun activity diagram dari halaman utama sebagai berikut.

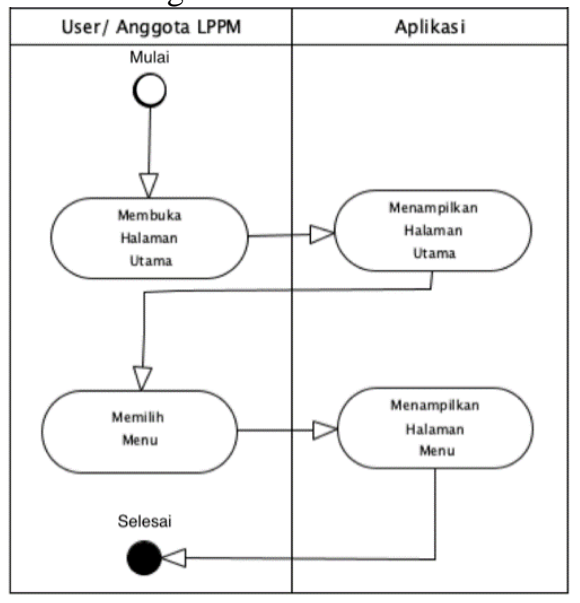

\section{Gambar 4.2 Activity Diagram Halaman Utama Aplikasi}

Dari gambar di atas pada saat user membuka tampilan masuk halaman utama maka aplikasi akan menampilkan tampilan halaman utama yang terdapat beberapa menu didalam halaman tersebut.

\section{Activity Diagram Ambil / Masukan gambar}

Adapun activity diagram Ambil / Masukan gambar pada aplikasi klasifikasi plagiarisme, sebagai berikut :

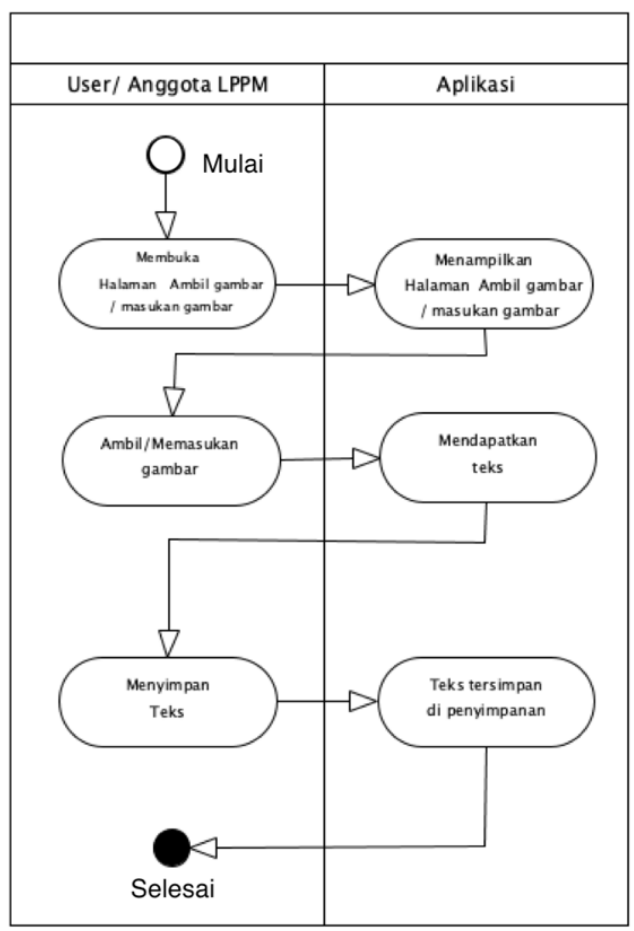

\section{Gambar 4.3 Activity Diagram Ambil / masukan gambar.}

Proses selanjutnya yaitu user memasukan atau mengambil gambar yang terdapat tulisan secara langsung untuk mendapatkan teks. Seteleh mendapatkan teks bisa langsung disimpan ke dalam penyimpanan.

\section{Activity Diagram Klasifikasi Plagiat}

Adapun activity diagram dari halaman utama sebagai berikut

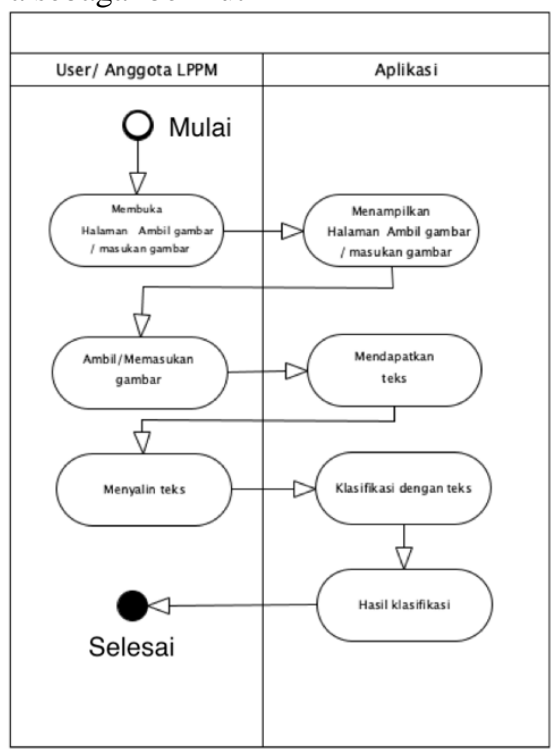

Gambar 4.4 Activity Diagram Klasifikasi Plagiat

Pada gambar berikut ini, merupakan aktifitas user dalam menyimpan hasil klasifikasi yang sudah dilakukan dengan cara screenshot layar kemudian menyimpan 
dalam bentuk gambar berekstensi (.png) kedalam penyimpanan internal

\section{c. Squence Diagram}

Squence Diagram menjelaskan permodelan sistem yang akan dibangun untuk menggambarkan interkasi antara obyek yang telah disusun dan merupakan tahap proses dari usecase diagram dan activity diagram.

\section{Squance Diagram Halaman Utama}

Gambar berikut ini adalah gambar sequence diagram saat user masuk ke halaman utama pertama kali.

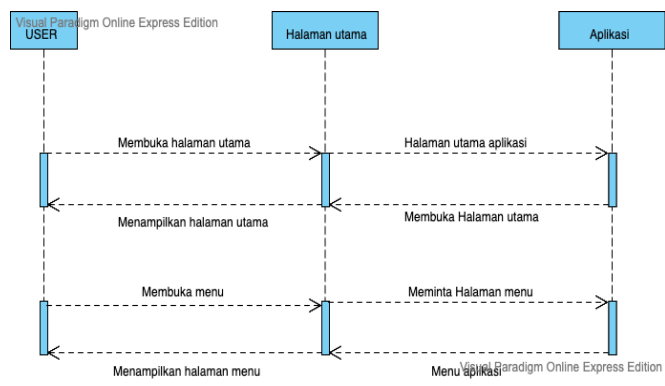

Gambar 4.5 Squence diagram user halaman utama

Pada gambar diatas, proses dimulai yaitu pada saat user membuka halaman utama pada aplikasi, kemudian pada halaman utama terdapat beberapa menu. Lalu selanjutnya ketika user membuka salah satu menu, aplikasi memberikan halaman pada setap menu yang ingin dibuka oleh user.

2. Squance Diagram Ambil / masukan foto

Gambar berikut ini adalah gambar sequence diagram saat user memasukan / mengambil gambar

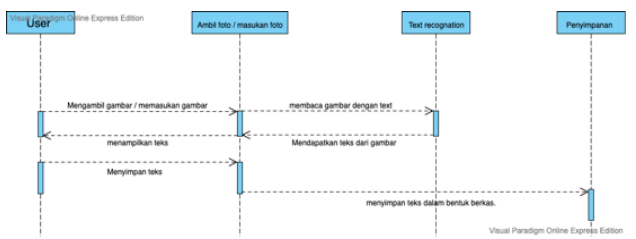

Gambar 4.6 Squence diagram user memasukan / ambil gambar

Pada gambar diatas, proses selanjutnya yaitu user mengambil atau memasukan gambar untuk mendapatkan teks dengan menggunakan fitur machine learning (text recognition), setelah mendapatkan teks user bisa langsung menyimpan hasil teks kedalam penyimpanan internal.

\section{d. Perancangan Interface}

Adapun perancangan dari tampilan interface dari sistem informasi penggelolaan data alumni pada SMA Ngeri 3 Sumbawa Besar.

\section{Perancangan Tampilan Halaman Utama}

Adapun perancangan tampilan halaman utama dari Aplikasi klasifikasi plagairisme dengan machine learning yang akan dibuat sebagai berikut :

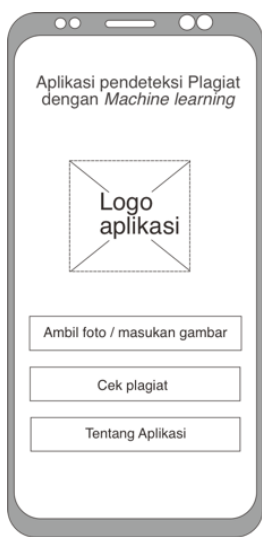

Gambar 4.7 Rancangan Tampilan ambil / masukan gambar

Tampilan halaman utama akan di buat logo beserta judul dari web yang akan dibuat dan terdapat 7 button untuk menu yang dapat di akses oleh user, dibawahnya terdapat slider dan berita dri sekolah.

Pada gambar di atas merupakan rancangan tampilan saat user memasuki menu aplikasi inti, terdapat 3(Tiga) menu utama , judul aplikasi, dan logo aplikasi. Menu yang pertama adalah menu 'Ambil foto / masukan gambar', Kedua menu 'Cek plagiat' dan yang ketiga menu 'Tentang Aplikasi'.

2. Perancangan Tampilan user Ambil / masukan foto

Berikut adalah perancangan dari tampilan ambil / masukan foto pada aplikasi klasifikasi plagairaisme dnegan machine learning sebagai berikut

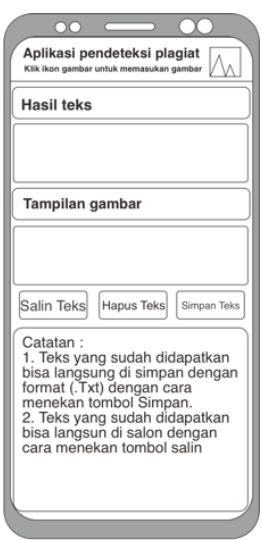

Gambar 4.8 Rancangan Tampilan ambil / masukan gambar 
Gambar di atas merupakan rancangan tampilan halaman menu ambil gambar /masukan gambar. Pada halaman ini terdapat nama judul aplikasi , icon gambar, terdapat kolom hasil teks, tampilan gambar, 3(dua) buah tombol yaitu tombol 'Salin teks', 'Hapus teks' dan 'Simpan teks' dan terdapat catatan penggunaan.

\section{Implementasi Interface}

Setelah melakukan pembuatan perancangan tampilan Aplikasi klasifikasi plagairisme dengan machine learning dengan menggunakan mockup, langkah selanjutnya adalah membuat antar muka sistem yang merupakan langkah untuk membangun interaksi aplikasi dengan user yang konsisten dan efektif.

\section{Impelementasi Tampilan Splashscreen}

Adapun implementasi tampilan Splashscreen yang telah dirancang sedemikian rupa sebagai berikut:

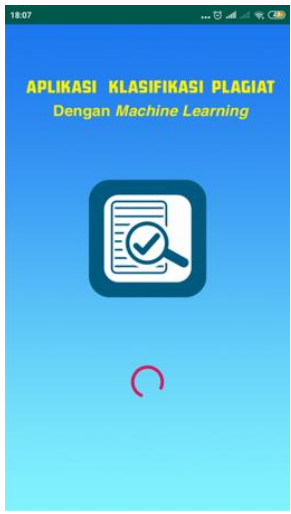

Gambar 4.10 Rancangan tampilan Splashscreen

Pada gambar diatas merupakan tampilan Splash screen aplikasi klasifikasi plagiarisme dengan memanfaatkan machine learning berbasis Android ketika aplikasi pertama kali dibuka.

\section{Implementasi Halaman Utama}

Adapun bentuk implemetasi dari perancangan tampilan dari Halaman utama Aplikasi :

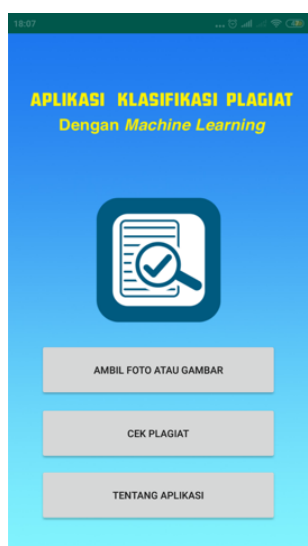

Gambar 4.9 Implementasi Halaman utama

Pada gambar diatas merupakan tampilan halaman utama pada aplikasi klasifikasi plagiarisme dengan machine learning. Terdapat 3(tiga) buah tombol menu, yaitu tombol 'Ambil foto atau gambar', tombol 'cek plagiat', tombol 'tentang kami'. Pada tombol 'ambil foto atau gambar' ketika di klik maka akan membuka halaman menu tersebut. Pada halaman tersebut terdapat fitur machine learning untuk mendapatkan teks dengan cara memasukan gambar dan dapat menyimpan dan menyalin teks tersebut. Pada tombol 'cek plagiat' ketika di klik akan membuka halaman klasifikasi plagiat dengan cara memasukan teks. Dan juga dapat melihat hasil klasifikasi serta dapat menyimpannya dalam bentuk gambar (.Png) langsung kedalam penyimpanan.

\section{Pengujian}

Adapun hasil pegujian dari perangkat lunak yang dilakukan mengunakan pengujian black box.

\section{Pengujian Menu User}

Pengujian perangkat lunak pada user terdiri dari memasukan gambar, mendapatkan teks dan menyimpan, klasifikasi / cek plagiat dengan teks, data hasil klasifikasi, detail klasifikasi, menyimpan hasil, dan halaman tentang aplikasi. 


\begin{tabular}{|c|c|c|c|c|}
\hline \multicolumn{5}{|c|}{ Kasus dan Hasil Uji } \\
\hline No & $\begin{array}{l}\text { Aksi } \\
\text { Actor }\end{array}$ & Harapan & $\begin{array}{l}\text { Hasil } \\
\text { Pengamat } \\
\text { an }\end{array}$ & $\begin{array}{l}\text { Kesi } \\
\text { mpul } \\
\text { an }\end{array}$ \\
\hline 1. & $\begin{array}{l}\text { Memulai } \\
\text { Aplikasi }\end{array}$ & $\begin{array}{l}\text { Menam } \\
\text { pilkan } \\
\text { halaman } \\
\text { splash } \\
\text { screen }\end{array}$ & 司 & $\begin{array}{c}\text { Sesua } \\
\mathrm{i}\end{array}$ \\
\hline 2. & $\begin{array}{l}\text { Membuk } \\
\text { a } \\
\text { Halaman } \\
\text { Utama } \\
\text { pada } \\
\text { Aplikasi }\end{array}$ & $\begin{array}{l}\text { Menampil } \\
\text { kan } \\
\text { halaman } \\
\text { utama dan } \\
\text { menampilk } \\
\text { an } 3 \text { (Tiga } \\
\text { menu) }\end{array}$ & 国 & $\begin{array}{c}\text { Sesua } \\
\mathrm{i}\end{array}$ \\
\hline 3. & $\begin{array}{l}\text { Membu } \\
\text { ka } \\
\text { Halama } \\
\mathrm{n} \\
\text { Ambil/ } \\
\text { masuka } \\
\text { n foto }\end{array}$ & $\begin{array}{l}\text { Menampi } \\
\text { Ikan } \\
\text { halaman } \\
\text { ambil/ } \\
\text { masukan } \\
\text { foto } \\
\text { dengan } \\
\text { terdapat } \\
\text { hasil teks } \\
\text { dan } \\
\text { tampilan } \\
\text { gambar. }\end{array}$ & 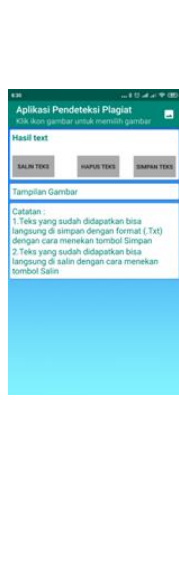 & $\begin{array}{c}\text { Sesua } \\
\mathrm{i}\end{array}$ \\
\hline
\end{tabular}

\section{KESIMPULAN DAN SARAN}

\subsection{Kesimpulan}

Dari hasil analisis dan perancangan sistem yang telah dilakukan, maka penulis dapat mengambil kesimpulan bahwa 'Rancang bangun aplikasi klasifikasi plagairisme dengan memanfaatkan machine learning berbasis Android telah selesai dibangun menggunakan Android Studio dan fitur API Copyleaks cloud computing. Dengan demikian aplikasi ini dapat memberikan konstribusi untuk membantu menjalankan visi LPPM Universitas Teknologi Sumbawa yaitu tidak adanya unsur plagiarisme pada pembuatan jurnal umum.

\subsection{Saran}

Dari hasil pembuatan Aplikasi klasifikasi plagiarisme dengan machine learning pada LPPM Universitas Teknologi Sumbawa, penulis memberikan saran agar pada tahap selanjutnya dilakukan pengembangan aplikasi diantara lain meliputi Penambahan icon searching untuk mencari hasil klasifikasi yang telah dilakukan, penambahan menu pilihan memasukan berkas "softfile" untuk dilakukan cek plagiat, dan penambahan desain interface agar lebih menarik.

\section{DAFTAR PUSTAKA}

[1] Simarmata, Janner. 2010. Rekayasa Perangkat Lunak.Yogyakarta: Penerbit ANDI .Yogyakarta.

[2] Pressman, Roger S. (2012). Rekayasa Perangkat Lunak (Pendekatan Praktisi) Edisi 7: Buku 1. Terjemahan oleh Adi Nugroho. Yogyakarta: Andi.

[3] Pilipus, Agustinus. (2017). Aplikasi Pendeteksi Plagiarisme Karya Tulis Ilmiah dengan Algorima Karbin Karb.Yogyakarta:Program Sarjana Teknik Infromatika Universitas Sanata Dharma.

[4] Alpaydin, Ethem. 2016. "Machine Learning : The New AI". United States of America: Toppan Best-Set Pramedia.

[5] Ladjamudin, Al - Bahra bin. 2005. Analisis dan Desain Sistem Informasi. Yogyakarta: Graha Ilmu. 
